\title{
Kinetic Study of Thermal 1,3-Dipolar Cycloaddition of Azomethine Ylides using Differential Scanning Calorimetry as Monitoring Window
}

\author{
Juan Mancebo-Aracil, ${ }^{[a]}$ María J. Muñoz-Guillena, ${ }^{[\mathrm{b}]}$ Ion Such-Basáñez ${ }^{[\mathrm{b}]}$ and \\ José M. Sansano-Gil ${ }^{*[a]}$
}

This paper is dedicated to Prof. Carmen Nájera on the occasion of her $60^{\text {th }}$ birthday

Abstract Text. Kinetics of 1,3-dipolar cycloaddition involving azomethine ylides, generated from thermal [1,2]-prototropy of the corresponding imino ester, employing differential scanning calorimetry (DSC), is surveyed. Glycine and phenylalanine derived imino esters have different behavior. The first one prefers reacting with itself at $75{ }^{\circ} \mathrm{C}$, rather than with the dipolarophile. However, the $\alpha$-substituted imino ester gives the cycloadduct at higher temperatures. The thermal dynamic analysis by ${ }^{1} \mathrm{H}$ NMR of the neat reaction mixture of the glycine derivative reveals the presence

\section{Introduction}

The general term thermal analysis (TA) is used to describe analytical experimental techniques which investigate the behavior of a sample reaction as a function of the temperature. Differential scanning calorimetry (DSC) is frequently used to obtain a wealth of information about a material or a reaction, kinetic parameters being one of the most important data. ${ }^{1}$ Wide-ranging applications in the field of polymer science, plastics, foods and pharmaceuticals, glasses and ceramics, proteins and life science materials, etc., have been documented. Also, valuable applications of TA in many industries have been found. ${ }^{[1]}$ A DSC analyzer measures the energy changes that occur as a sample is heated, cooled or held isothermally, together with the temperature at which these changes take place. One of the major advantages of DSC is that samples are very easily encapsulated, usually with little or no preparation, ready to be placed in the DSC, so that measurements can be quickly and easily made. Additionally, due to electromechanical advances, data obtained by high performance calorimeters and thermobalances can give extremely accurate and reproducible quantitative measurements (including kinetic data) that occur in the sample. ${ }^{[2][3]}$ of signals corresponding to the dipole in very small proportion. The non-isothermal and isothermal DSC curves of the cycloaddition of phenylalaninate and diisobutyl fumarate are obtained from freshly prepared samples. The application of known kinetic models and mathematical multiple non-linear regressions (NLR) allow to determine and to compare $E_{a}, \operatorname{InA}$, reaction orders, and reaction enthalpy. Finally a rate equation for each different temperature can be established for this particular thermal cycloaddition.
Concerning kinetic analysis, the detection, identification and estimation of concentrations of species present in a reaction has been accomplished by chromatographic and spectroscopic techniques, mass spectrometry, laser devices, fluorescence, photoelectron spectroscopy and NMR experiments. ${ }^{[4]}$ In this study, the heat flow, obtained from DSC experiments, is used as a kinetic survey of the 1,3-dipolar cycloaddition (1,3-DC) due to its proportionality with respect to the reaction rate. This is true for exothermic reactions in which heat flow is controlled by the kinetics of the reaction, while this assumption does not hold true for endothermic reactions where the heat flow is controlled by the heat transfer between the sample and the apparatus. ${ }^{[5]}$

\footnotetext{
[a] J. Mancebo-Aracil and Dr. J. M. Sansano-Gil Departamento de Química Orgánica e Instituto de Síntesis Orgánica (ISO), Universidad de Alicante, 03080-Alicante (Spain) Fax: (+34-965903549) E-mail:imsansano@ua.es

[b] Dr. M. J. MuñozGuillena, and I. Such-Basáñez Servicios Técnicos de Investigación, Universidad de Alicante, 03080-Alicante (Spain)
}

Supporting information for this article is available on the WWW under http://dx.doi.org/10.1002/cplu.200xxxxxx.((Please delete if not appropriate)) 
Many organic substances have been submitted to these types of tests but, to the best of our knowledge, no bimolecular organic reaction has been deeply analyzed ${ }^{[6]}$ employing DSC techniques. Thermal 1,3-DC of imino esters and diisobutyl fumarate would be a suitable transformation to be kinetically analyzed by DSC. ${ }^{[7]}$ Since the seminal Hüisgen contribution in the early $1960 \mathrm{~s},{ }^{[8]} 1,3-\mathrm{DC}$ have been extensively studied from a theoretical point of view, ${ }^{[9]}$ and experimentally applied for many purposes. ${ }^{[10]}$ Despite of the efforts dedicated to survey this type of cycloadditions, several aspects are not clear, such as the presence of ionic or diradical or pseudo-diradical species $^{[11]}$ in the transition states for thermally induced generation of 1,3-dipoles, the detection of migrations able to promote the existence of them, etc.

In this work, we will determine the kinetic parameters of the above mentioned thermal 1,2-prototropy of imino esters selecting DSC as technical tool. Also, a comparison of these kinetic parameters employing different mathematical models, will be made.

\section{Results and Discussion}

Azomethine ylides are one of the most frequently employed 1,3-dipoles in organic synthesis ${ }^{[12]}$ and, particularly, for the construction of pyrrolidines. There are many strategies for preparing them, ${ }^{[10 b]}$ 1,2-prototropy of $\alpha$-imino ester type-1 (Scheme 1) being widely employed as a fast strategy. The reaction can be performed from the isolated imine type- 1 plus the dipolarophile, or through a multicomponent one pot imine formation-cycloaddition. Initially, neat $\mathbf{1}(2.753 \mathrm{mg}$ in a sealed crucible) underwent a thermal study in order to detect a small exothermic process revealing the existence of such rearrangement to yield $\mathbf{2}$ (always freshly prepared samples were used for analyses). Figure 1 showed that, under a 10 ${ }^{\circ} \mathrm{C} \cdot \mathrm{min}^{-1}$ heating rate, an exothermic process started approximately at $75{ }^{\circ} \mathrm{C}$, however the transfer of heat seemed too high for the generation of intermediate 2 . The reversibility of the process indicated in Scheme 1 is not in agreement with such a large heat flow. Therefore, another DSC experiment consisting on iterative cycles of heating-cooling, up to a temperature in the very initial stages of the reaction $\left(80^{\circ} \mathrm{C}\right)$, was employed for demonstrating the described equilibrium (Figure 2). However, the repeated cycles of heating revealed that each time the sample was reheated the observed heat flow became lower so, a consumption of the starting imine 1 was bound to be occurring. The ${ }^{1} \mathrm{H}$ NMR of the thermally transformed sample revealed that the imino ester 1, after suffering the 1,2-proton migration, reacted with itself to afford, almost quantitatively, a mixture of diastereomeric imidazolidines $3^{[13]}$ (Scheme 2). The peak observed in Figure 1 corresponds to an exothermic reaction, and the complete area of the heat flow is equivalent to the enthalpy of the whole transformation to afford them.

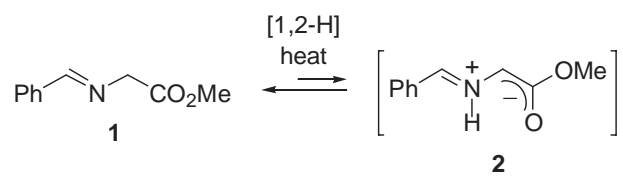

Scheme 1. Thermal generation of stabilized azomethine ylides.

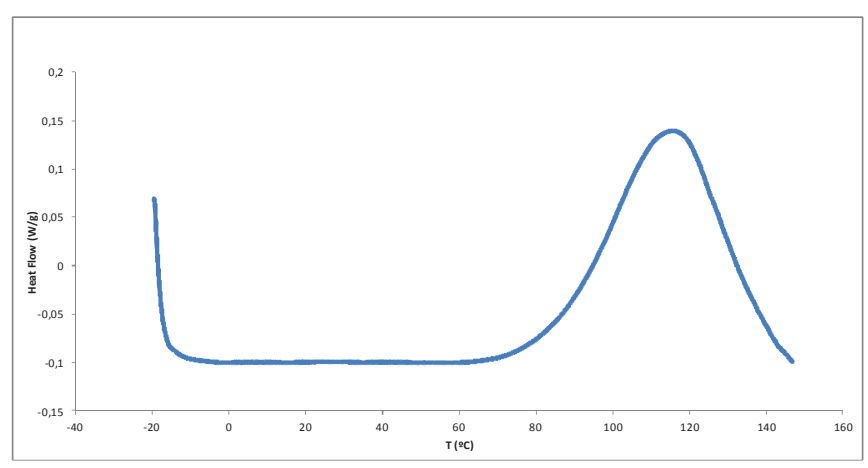

Figure 1. DSC curve at $10^{\circ} \mathrm{C} \cdot \mathrm{min}^{-1}$ heating slope of imine 1.

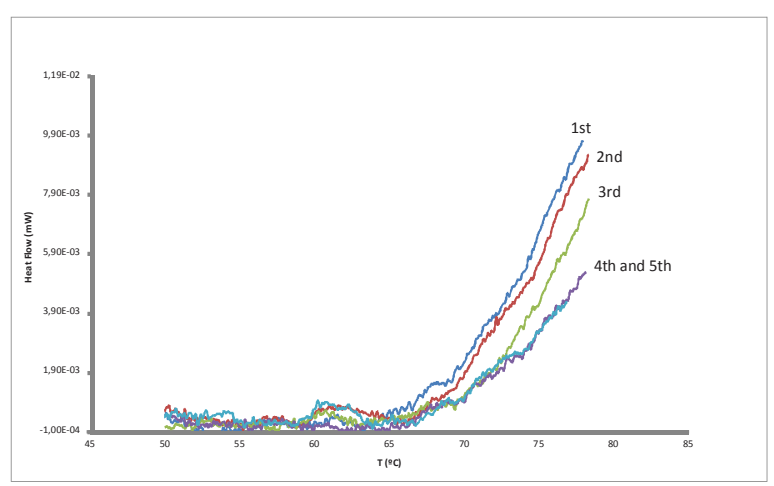

Figure 2. Several iterative DSC heating-cooling cycles of imine 1.

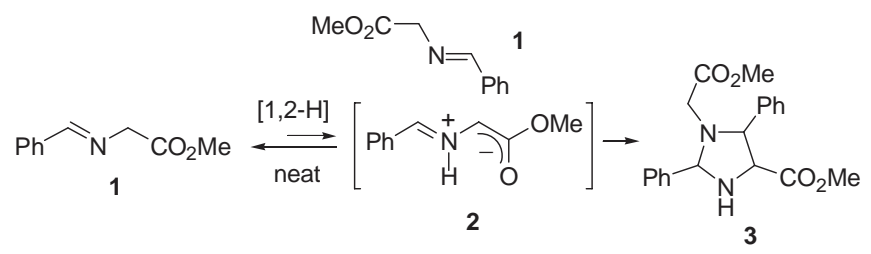

Scheme 2. Synthesis of imidazolidines 3 during thermal experiments.

With all these results derived from the fast reaction of imine 1 with itself, the addition of a dipolarophile such as diisobutyl fumarate to the dipole 2 seemed to be a difficult task. In fact, when a mixture of imine 1 and diisobutyl fumarate were allowed to undergo the analogous heating program showed in Figure 1 , the resulting plot was nearly identical. Also, ${ }^{1} \mathrm{H}$ NMR 
experiment of the crude material indicated the presence of imidazolidine $\mathbf{3}$ and unaltered fumarate. Isobutyl fumarate was selected due to its liquid nature at ambient conditions and because a homogeneous solution was obtained by mixing it with the imino ester $\mathbf{1}$ or $\mathbf{4}$. By contrast, dimethyl fumarate, which is a solid at room temperature, formed heterogeneous mixtures with the imino esters and the heat absorption corresponding to its melting process, at $102{ }^{\circ} \mathrm{C}$, notably interfered with the reaction heat flow.

Taking into account that the formation of the dipole 2 could not be demonstrated, and the reaction of $\mathbf{1}$ with itself started at around $80{ }^{\circ} \mathrm{C},{ }^{1} \mathrm{H}$ NMR and ${ }^{13} \mathrm{C}$ NMR experiments were run at different temperatures using deuterated DMSO as solvent. The higher sensitivity of ${ }^{1} \mathrm{H}$ NMR was crucial to obtain some evidences of the 1,3-dipole. In the first attempt, the mixture formed by imine 1 and diisobutyl fumarate in DMSO- $d_{6}$ was allowed to raise $130 \stackrel{\circ}{ } \mathrm{C}$ and no relevant signals of the betaine 2 were observed, but noticeable amounts of imidazolidine $\mathbf{3}$ were detected instead. The dipolarophile was not able to capture dipole 2 in this solution. ${ }^{1} \mathrm{H}$ NMR experiments were then performed reproducing the identical thermal conditions of the calorimeter. So, neat freshly prepared imino ester 1 was placed (in the absence of fumarate) in an NMR tube with a coaxial capillary tube containing DMSO- $d_{6}$ and the temperature increased $5{ }^{\circ} \mathrm{C} \cdot \mathrm{min}^{-1}$. Such as it occurred in the DSC experiment at $75^{\circ} \mathrm{C}$ amounts of $\mathbf{3}$ were observed. In addition, a small signal at $5.87 \mathrm{ppm}$ was registered in the experiments run at $60{ }^{\circ} \mathrm{C}$ and at higher temperatures, together with a peak with identical intensity at $8.01 \mathrm{ppm}$ (Figure 3). Both signals disappeared when the experiment was cooled at room temperature and immediately appeared by heating back to 60 ${ }^{\circ} \mathrm{C}$. This behavior was repeatedly observed even after seven heating-cooling cycles. There are several examples of ${ }^{1} \mathrm{H}$ NMR spectra of imino ester-derived enolates in the literature but none of them is identical to dipole $2^{\left[{ }^{[14]}\right.}$ Calculations by NMR simulators for similar systems predicted an upfield shift of the iminic hydrogen (7.9-8.0 ppm) with respect to imine 1 whether a enol-type structure was considered. However, the downfield shift of the $\alpha$-proton of the dipole 2 is very notable (5.25-6.90 ppm range). ${ }^{[15]}$ At $60 \stackrel{\circ}{ }{ }^{\circ}$ the imine 1 :dipole 2 ratio was close to $100: 2$, but this ratio was slightly higher (100:4 or 100:5) when the temperature was maintained above $75^{\circ} \mathrm{C}$.

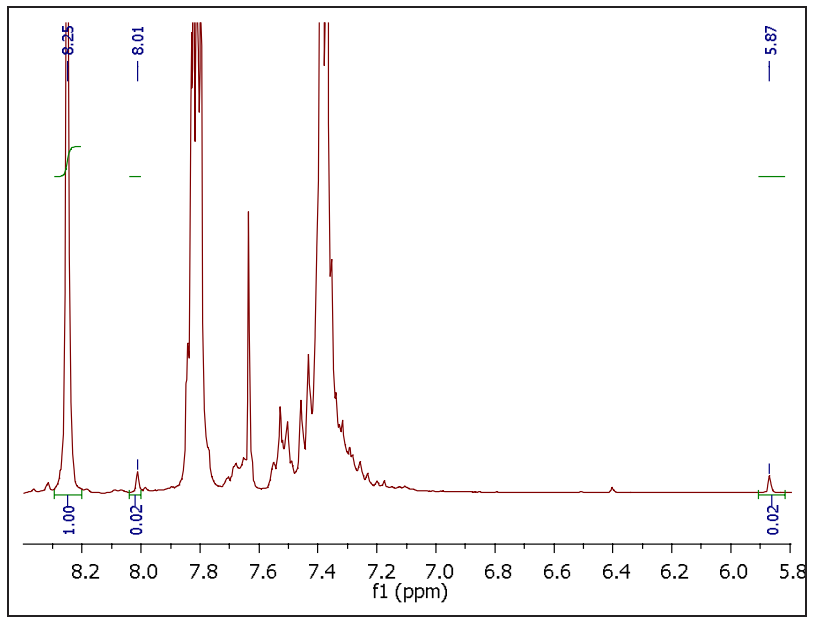

Figure 3. ${ }^{1} \mathrm{H}$ NMR spectra of the neat mixture showing two small signals corresponding to dipole 2 .

The reduction of the reactivity of imino ester $\mathbf{1}$ was achieved by bonding a benzyl radical to its $\alpha$-position. Thus, when 1,3-dipole precursor 4 was submitted to a heating rate of $10 \stackrel{\circ}{ } \mathrm{C} \cdot \mathrm{min}^{-1}$ from -20 to $200 \stackrel{\circ}{\circ}$ no exothermic peak was detected and compound 4 was recovered without any significant decomposition (Figure 4, dashed line). The solventfree homogeneous liquid mixture of imino ester $\mathbf{4}$ and diisobutyl fumarate was next analyzed under the analogous conditions of the calorimeter. Monitoring-DSC experiment revealed that an exothermic process, corresponding to the expected 1,3-DC (Scheme 3) started at approximately $120 \stackrel{\circ}{\circ}$ finishing at $260{ }^{\circ} \mathrm{C}$ (Figure 4, solid line). The crude product 5 was obtained ( $5 \mathrm{mg}$ from the sealed crucible) as a 3:1 mixture of the endo:exo diastereoisomers according to NOESY experiments, and by comparison of the proton coupling constants of similar structures.

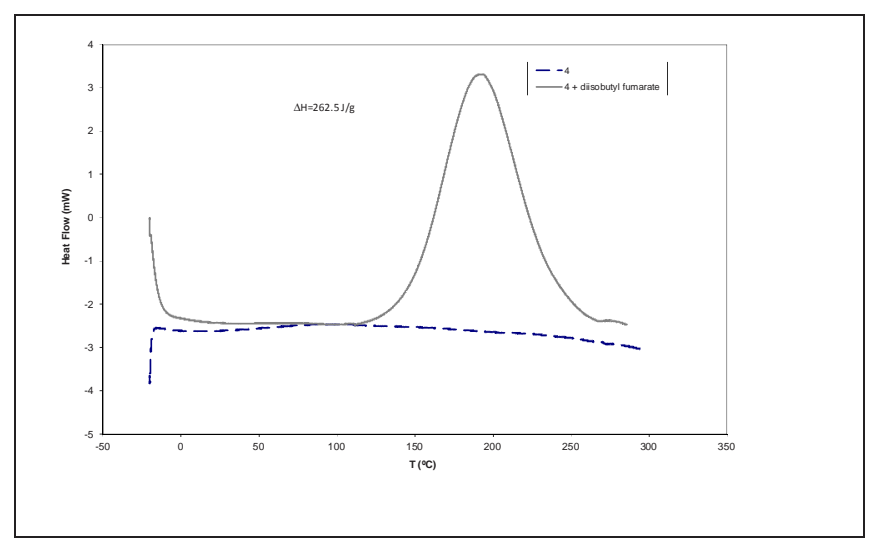

Figure 4. Dynamic DSC curve $\left(10 \stackrel{\circ}{\circ} \cdot \mathrm{min}^{-1}\right)$ of the reaction between imine 4 and diisobutyl fumarate (solid line) and the absence of reaction of $\mathbf{4}$ with itself (dashed line)..

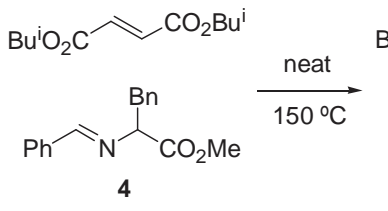

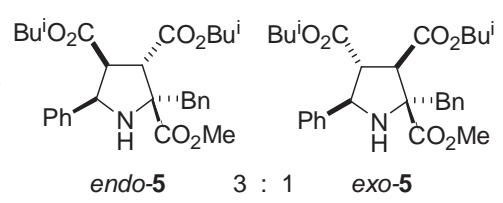

Scheme 3. Thermal reaction between imino ester $\mathbf{4}$ and diisobutyl fumarate to yield proline derivatives 5 .

This solvent-free organic synthesis ${ }^{[16]}$ ensures a fast transformation and, in consequence a fast analysis, reducing pollution, costs and raw materials. ${ }^{[17]}$ Also, the stereoselectivity obtained (Scheme 3) was better than the analogous detected when the same reaction was carried out, for $24 \mathrm{~h}$, in refluxing xylene as solvent $(0.33 M){ }^{[18]}$ 
Before studying kinetics of the 1,3-DC drawn in Scheme 3, basic isothermal DSC experiments were performed. The information obtained from Figures 5 and 6 , together with the extracted from Figure 4 (above) is crucial. In order to select the best temperature to carry out the kinetic studies a set of temperatures were tested for evaluating the reaction conversion vs reaction time ${ }^{[19]}$ Figure 5 shows a extremely fast transformation at $150 \stackrel{\circ}{\circ}$. Also isothermal heat flow vs. time was represented at $110^{\circ} \mathrm{C}$ (as an example) to show the better reaction temperature to measure the kinetic parameters (Figure 5). At that time (50 min for the reaction at $150{ }^{\circ} \mathrm{C}$, and $150 \mathrm{~min}$ for the reaction at $110^{\circ} \mathrm{C}$ ) the conversion was judged complete according to ${ }^{1} \mathrm{H}$ NMR. On the other hand, the bell shaped DSC heat flow vs time curves (e. g. $110^{\circ} \mathrm{C}$ experiment in Figure 5) suggested the existence of an autocatalytic reaction mechanism. ${ }^{[20]}$ Also, a reaction is considered as autocatalytic when the concentration (conversion) of one component vs $t$ plot exhibits an S-shape profile ${ }^{[21]}$ (Figure 6). This phenomenon is often ignored in chemistry, but it is very well known that a 1,3-DC of imino esters and alkenes is accelerated by the employment of bases and Lewis acids, so the final pyrrolidine $\mathbf{5}$ would act as autocatalyst of the model reaction (Scheme 3). ${ }^{[10]}$

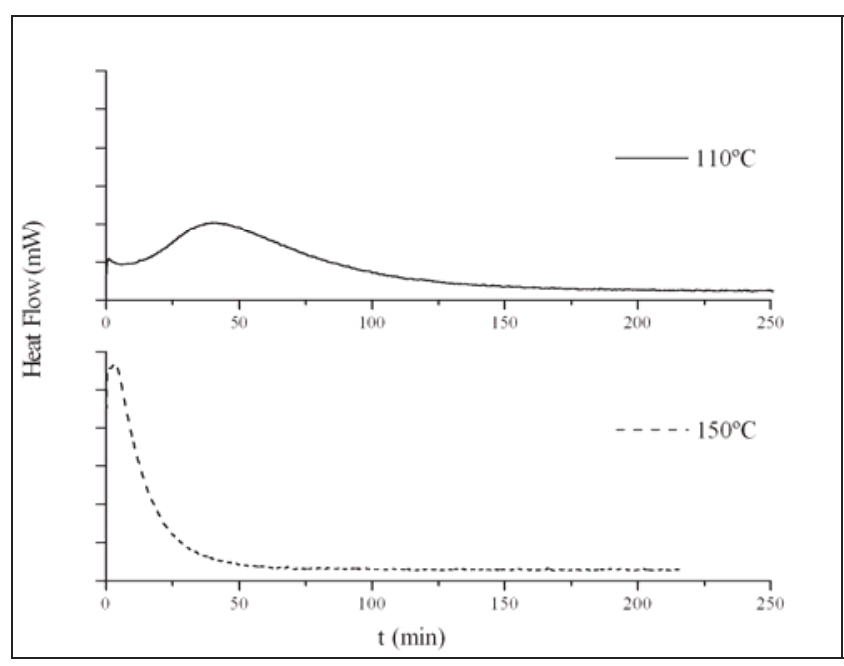

Figure 5. Isothermal plots of the reactions between $\mathbf{4}$ and diisobutyl fumarate performed at $110 \stackrel{\circ}{\mathrm{C}}$ and $150 \stackrel{\circ}{\mathrm{C}}$

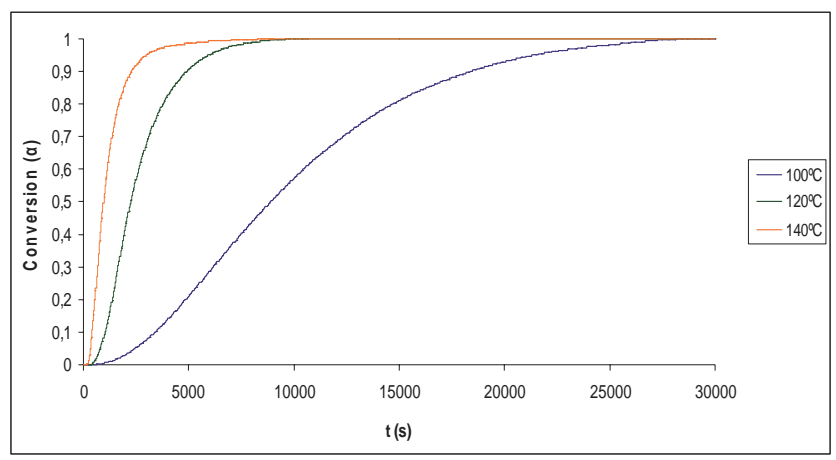

Figure 6. Conversion vs $t$ plots of the reactions between 4 and disobutyl

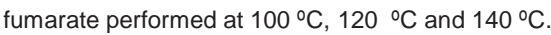

\section{Kinetic information obtained from non-isothermal (dynamic) DSC experiment. ${ }^{[22]}$}

Several TA kinetic models or specific tests can be applied to investigate the kinetic parameters of this reaction. It is common the use of methods or models that rely on dynamic, nonisothermal experiments ${ }^{[5]}$ such as Kissinger's, ${ }^{[23]}$ BorchardtDaniels' (BD) ${ }^{[24]}$ Ozawa's, and Ozawa-Flynn-Wall's (OFW's) ${ }^{[25]}$ methods. Although the BD method was originally developed for DTA studies of homogeneous liquid-phase reactions with no mass loss, it assumes that the reaction follows $n^{\text {th }}$ order kinetics, so it would be rather helpful for the calculation of reaction order and $E_{a}$ and later to compare those values with the analogous ones obtained by application of the other models. ${ }^{[6]}$ Non-isothermal (first order) Kissinger's and OFW's methods were designed for homogeneous solid samples, however it has been applied to liquid ones. ${ }^{[26]}$ Despite the recent development of wide advanced computational methods for the kinetic analysis of thermoanalytical experiments, the accuracy and simplicity of the Kissinger's method is still commonly used. ${ }^{[27]}$ The usual starting point for kinetic analysis of non-isothermal data is:

$\mathrm{d} \alpha / \mathrm{d} T=(\mathrm{d} \alpha / \mathrm{d} t)(\mathrm{d} t / \mathrm{d} T)=(\mathrm{d} \alpha / \mathrm{d} t)(1 / \beta)$

where $\alpha$ is the reaction conversion and $\beta$ is the heating rate.

Based on an Arrhenius behavior, and working at 50\% conversion (peak maximum of DSC plot), Kissinger's method ${ }^{[5]}$ involves the use of the second derivative of equation (2). As this derivative must be zero at the inflexion point of a DSC curve, and considering $\left(1-\alpha_{\max }\right)$ is a constant for a given value of $n$, equation (2) can be transformed in equation (3). ${ }^{[28]}$

$\mathrm{d} \alpha / \mathrm{d} T=(A / \beta) \exp -\left(E_{a} / R T\right)(1-\alpha)^{\mathrm{n}}$

$\ln \left(\beta / T_{\max }{ }^{2}\right)=$ constant $-\left(E_{a} / \mathrm{R}\right)\left(1 / T_{\max }\right)$

This method allows to obtain the activation energy $\left(E_{a}\right)$ of the 1,3-DC between 4 and diisobutyl fumarate (Scheme 3) after plotting $\ln \left(\beta / T_{\max }{ }^{2}\right) v s\left(1 / T_{\max }\right)$ for a series of experiments at different heating rates $\left(1^{\circ} \mathrm{C} \cdot \mathrm{min}^{-1}\right.$ to $\left.20^{\circ} \mathrm{C} \cdot \mathrm{min}^{-1}\right)$. It is worth to notice that $T_{\max }$ temperatures were corrected according to ASTM E698-11 to account instrumental differences due to thermal lag and sample overheating. ${ }^{[29]}$ Calculations showed a good linear correlation ${ }^{[30]}$ obtaining a corrected $E_{a}$ value of $68.08 \mathrm{~kJ} \cdot \mathrm{mol}^{-1}$ for the Kissinger method, which also provided a good approach to the pre-exponential factor A (Table 1, entry 1).

The OFW method (refined Ozawa's model) is applicable to the integral-type DTA curves. A group of DSC curves obtained 
at more than four heating rates are necessary. The DSC curves shift to higher temperature with increasing heating rates, the temperature and flow rate data being obtained at the same conversion (peak maximum, 50\% conversion). Final equation (4) of the OFW approach also permitted to calculate $E_{a}$ from the slope of the plot of $\ln (\beta) v s(1 / T)$, which correlated well with a coefficient of $0.993,{ }^{[30]}$ and after further refinement of the value, a $E_{a}$ value of $63.99 \mathrm{~kJ} \cdot \mathrm{mol}^{-1}$ was obtained (Table 1 , entry 2). ${ }^{[29]}$ The difference between the activation energies of Kissinger's and OFW's methods was $4 \mathrm{~kJ} \cdot \mathrm{mol}^{-1}$, which encouraged us to evaluate the application of both, $\mathrm{n}^{\text {th }}$ order and autocatalytic BD models to our system. $\mathrm{n}^{\text {th }}$ order BD did not afford good correlation values for the experimental data, while autocatalytic BD did (Table 1, entries 3-5). So, this model was selected for further inspection of kinetic data.

$\ln (\beta)=$ constant $-\left(E_{a} / \mathrm{R}\right)(1 / T)$

Table 1. Kinetic models applied to non-isothermal DSC curves

\begin{tabular}{|c|c|c|c|c|}
\hline & Model & $\ln A^{[a]}$ & $\begin{array}{l}E_{a} \\
\left(\mathrm{~kJ} \cdot \mathrm{mol}^{-1}\right)\end{array}$ & $\begin{array}{l}\text { Reaction order } \\
(n+m)\end{array}$ \\
\hline 1 & Kissinger & 16.92 & 68.08 & $1^{[\mathrm{b}]}$ \\
\hline 2 & OFW & 15.80 & 63.99 & $1^{[\mathrm{b}]}$ \\
\hline 3 & 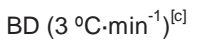 & 24.16 & 96.43 & $0.38+0.85$ \\
\hline 4 & 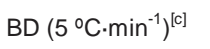 & 20.17 & 83.17 & $0.28+0.85$ \\
\hline 5 & 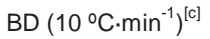 & 18.47 & 78.84 & $0.17+0.79$ \\
\hline
\end{tabular}

[a] A value expressed in $\left(\mathrm{s}^{-1}\right)$. [b] Standard overall order reaction. [c] Data calculated by using BD model [equation (5)].

The BD kinetics approach allows the calculation of $E_{a}, A$, rate constant and reaction order. For the autocatalytic process the original formula for material transitions such as curing, crystallization, melting, decomposition, etc., is shown in equation (5).

$\ln [\mathrm{d} \alpha / \mathrm{d} t]=\ln [\mathrm{k}(T)]+\mathrm{n} \ln [1-\alpha]+\mathrm{m} \ln [\alpha]$

This equation can be solved with a multiple linear regression (MLR) following the standard test method. ${ }^{[31][32]}$ Measurements taken between approximately 3-4\% (10\% of peak height) and $50 \%$ conversions revealed an excellent match with the mathematical equation and a very low error. However, for each of dynamic experiment, the values of $A, E_{a}$, $\mathrm{n}$ and $\mathrm{m}$ depicted on Table 1 (entries 3-5) are averaged trough the selected data range. Experiments run at 3,5 and 10 ${ }^{\circ} \mathrm{C} \cdot \mathrm{min}^{-1}$ offered reasonable results of pre-exponential factors with overall 1.0 reaction order. This restriction is the main drawback of autocatalytic BD approach according to the literature (Table 1, entries 3-5)..$^{[22 a][33]}$ The $\ln [\mathrm{k}(T)]$ vs $1 / T$ plot reported higher values of $E_{a}$ and InA than the analogous ones obtained by Kissinger or OFW methods.

The initial concentration of the sample was not considered in equation (5), so a minor modification of it is detailed in equation (6). This modified expression with $[4]_{0}=2.236 \mathrm{M}$ is equivalent to the general reaction rate concept [equation (7)], ${ }^{[34]}$ and also equivalent to the equation (5). If we consider that $\mathrm{BD}$ total reaction orders are very close to 1 , the difference between equations $(6)$ and $(5)$ is the term $(m+n-1) \cdot \ln \left[4_{0}\right]$, which is very close to zero. In this sense, equations (5) and (7) are equivalent according to $\mathrm{BD}$ model, and the resulting rate equation is just an approximation to the real one.

$\ln [4]_{0}[\mathrm{~d} \alpha / \mathrm{d} t]=\ln [\mathrm{k}(T)]+\mathrm{n} \operatorname{In}[4]_{0}[1-\alpha]+\mathrm{m} \operatorname{In}[4]_{0}[\alpha]$

$v=\mathrm{k}(T)[4]^{\mathrm{n}}[5]^{\mathrm{m}}$

A useful technique for DSC analysis is a free-kinetics mode ${ }^{[35]}$ based on the realization that the activation energy $E_{a}$ may depend on the degree of the reaction conversion. In this method, $E_{a}$ values obtained at different conversions were calculated applying Kissinger's methodology to the isoconversional DSC integral curves [slope of equation (3) R]. Figure 7 shows the variation of the $E_{a} v s$ conversion. At the beginning of the reaction ( $3 \%$ conversions) $E_{a}$ reached a maximum value of $72.5 \mathrm{~kJ} \cdot \mathrm{mol}^{-1}$. At this point, no or very little autocatalysis was taking place because the concentration of the product was very low. At higher levels of conversion (10$80 \%) E_{a}$ values decreased steadily giving an indication that as reaction proceeds, the autocatalytic mechanism takes advantage over the non-catalyzed processes. The higher the conversion is, the lower the activation energy is, which is in agreement with non-catalyzed and autocatalytic processes occurring at the same time but to a different extent as reaction proceeds.

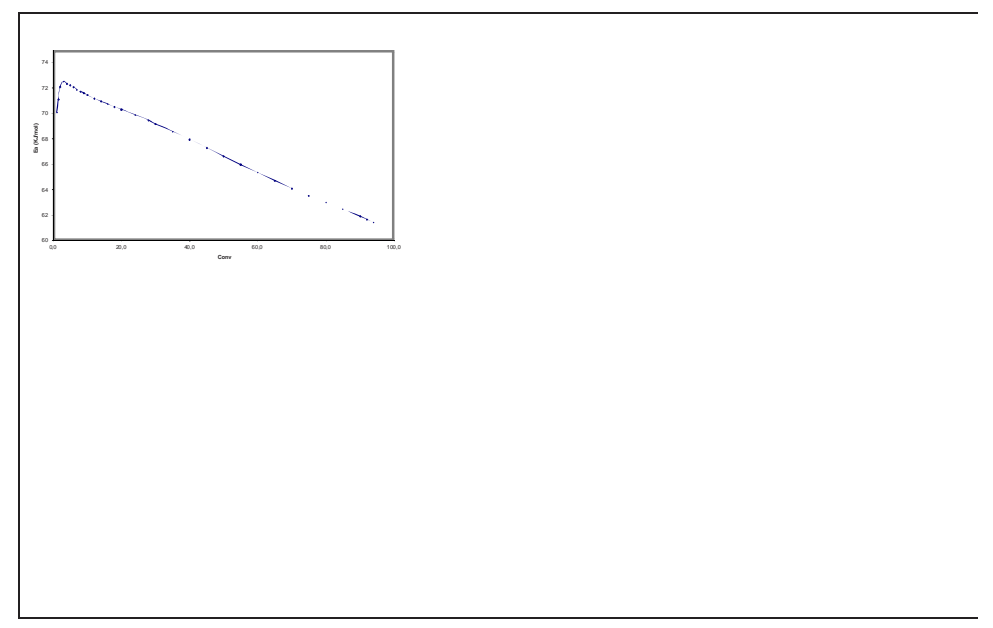

Figure 7. Variation of the $E_{a}$ vs conversion. 
A good estimation of the reaction enthalpy could be obtained from the integration of the corresponding nonisothermal DSC curves (Table 2). High heating rates (15 and $20 \stackrel{\circ}{\circ} \cdot \mathrm{min}^{-1}$ ) afforded elevated $\Delta H$ values so, the average energy of the recommended tests (up to $\left.10 \stackrel{\circ}{\circ} \mathrm{C} \cdot \mathrm{min}^{-1}\right)^{[22]}$ furnished $76.31\left(\mathrm{~kJ} \cdot \mathrm{mol}^{-1}\right)$.

\begin{tabular}{|lccc|}
\hline \multicolumn{4}{|c|}{ Table 2. Integrated $\Delta H$ values obtained at different heating rates. } \\
$\beta\left({ }^{\circ} \mathrm{C} \cdot \mathrm{min}^{-1}\right)$ & $\Delta H\left(\mathrm{~kJ} \cdot \mathrm{mol}^{-1}\right)$ & $\beta\left({ }^{\circ} \mathrm{C} \cdot \mathrm{min}^{-1}\right)$ & $\Delta H\left(\mathrm{~kJ} \cdot \mathrm{mol}^{-1}\right)$ \\
\hline 1 & 75.15 & 10 & 77.82 \\
3 & 75.89 & 15 & 80.59 \\
5 & 76.39 & 20 & 80.69 \\
\hline
\end{tabular}

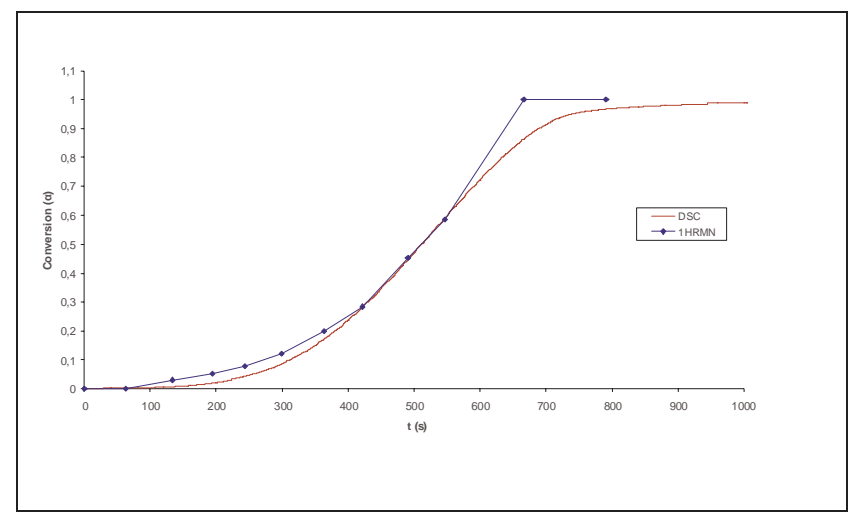

Figure 8. Comparison of isothermal plots of the reactions performed at 130 ${ }^{\circ} \mathrm{C}$ in a flask and in the calorimeter.

The rate expression of this reaction was studied employing isothermal TA experiments and data obtained from the stirred mixture. With more accurate conversions determined by DSC experiments the integrated rate expressions for first, second, and even third order were properly plotted and no linear correlation was observed. ${ }^{4 b}$ The application of pseudo-order techniques offered valuable information through the displacement of the conversion $v s t$ curves. Figure 9 shows conversions vs time plots calculated from DSC experiments run at $120^{\circ} \mathrm{C}$ with varying amounts of the different species involved in the reaction. When a double amount of diisobutyl fumarate was employed, DSC experiment indicated that the reaction rate was rather independent of the amount of dipolarophile employed (diisobutyl fumarate). ${ }^{[30]}$ However, when the DSC measurement reaction was performed employing double amount of imine 1 the reaction rate was accelerated (2-3 times faster). ${ }^{[30]}$ The addition of small amounts of pure pyrrolidine $5(2 \%)$ also produced an acceleration of the reaction, which supported its autocatalytic role. In this last test the initial induction period did not exist and, in consequence, the resulting S-shape plot disappeared (Figure 9). The data of both plots are shown in Figure 8 . In the case DSC experiment, the time taken to reach the temperature was approximately lower than $20 \mathrm{~s}$ with a high control of the temperature. For the conventional stirred neat reaction, using a digital thermometer immersed in the reaction mixture, the time taken to achieve $130 \stackrel{\circ}{\circ}$ was very close to $35 \mathrm{~s}$. The plots were almost identical at the beginning and overlap in the $25-65 \%$ conversion range. Around $70 \%$ and higher conversions, the DSC lags behind the stirred reaction giving an indication that diffusion limitations are present at these conversions. So, all measurements done by DSC in the range of $0-70 \%$ conversions ensure diffusion effects free data and are similar to the laboratory solventfree stirred conventional reaction.

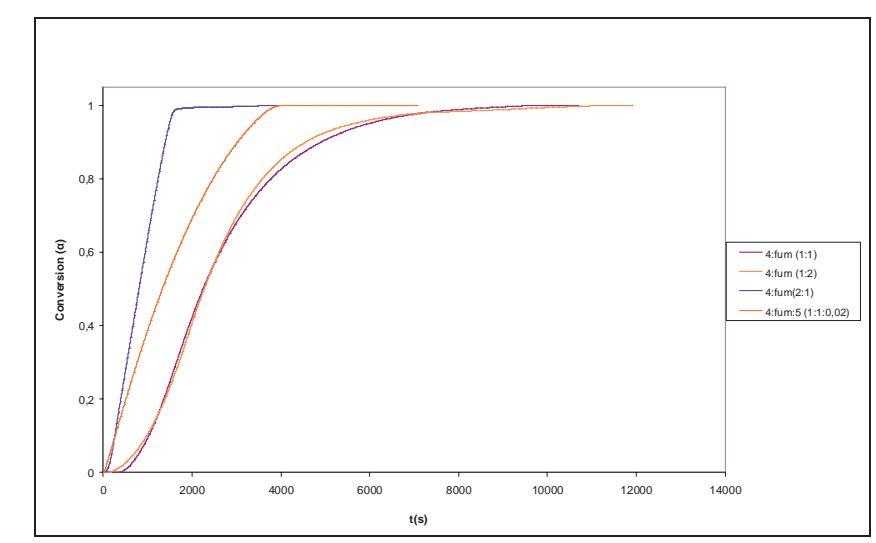

Figure 9. Pseudo-order experiments performed through DSC.

With several isothermal DSC curves in hand, we tried to adjust them to a mathematical expression analogous to equation (6), obtaining homogeneous $n$ and $m$ reaction orders 
starting from conversions closed to $3 \%$ (10\% of peak height). Experimentally, when the sample is introduced to the preheated furnace an important fluctuation of the temperature occurred and it is not appropriate to take data until the thermal equilibrium is settled again. So, the following conversion ranges $3 \%-50 \%$ (Table 3 ), $3 \%-60 \%,{ }^{[30]}$ and $3-70 \%{ }^{[30]}$ were considered for the study, the last one being in the limit where diffusion becomes a serious inconvenient. Even when data close to diffusion limitations was considered, the kinetic parameters obtained were very similar (see Table 4). Data obtained for the analysis $3 \%-50 \%$ is detailed in Table $3,{ }^{[30]}$ where $\operatorname{lnk}(T), \mathrm{m}$ and $\mathrm{n}$ reaction orders and adjustment error are shown. Regardless the range of conversion taken in the study, we observe that the values of the reaction orders are almost constant. The total reaction order can be estimated in around 1.7 as an average of the five essayed temperatures, where 0.5 partial reaction order corresponded to the concentration of cycloadduct 5 (Tables 3 and 4). This method also affords consistent both $E_{a}\left(67.47 \mathrm{~kJ} \cdot \mathrm{mol}^{-1}\right)$ and pre-exponential term $\left(\ln A=13.007, A=4.46 \cdot 10^{5}\right)$ (averaging values in Table 4), which were calculated from the linear plot of $\{\operatorname{lnk}(T)\} v s T^{-1}$. ${ }^{30]}$ The most relevant aspect is that it is possible to write the rate equation for this autocatalyzed 1,3-DC under different operation temperatures (Table 5). ${ }^{[36]}$

\begin{tabular}{|c|c|c|c|c|}
\hline$T\left({ }^{\circ} \mathrm{C}\right)$ & $\operatorname{lnk}(T)$ & $\mathrm{n}$ order & $\mathrm{m}$ order & $\Sigma \operatorname{error}^{2[a]}$ \\
\hline 100 & -9.0461 & 1.360 & 0.545 & 9.41 \\
\hline 110 & -7.8495 & 0.945 & 0.495 & 4.94 \\
\hline 120 & -7.4569 & 1.105 & 0.509 & 5.80 \\
\hline 130 & -7.1100 & 1.123 & 0.489 & 2.34 \\
\hline 140 & -6.7965 & 1.430 & 0.485 & 2.14 \\
\hline
\end{tabular}

[a] Determined by solver mathematical NLR of the DSC plot.

\begin{tabular}{|c|c|c|c|}
\hline Conversion & $E_{a}\left(\mathrm{~kJ} \cdot \mathrm{mol}^{-1}\right)$ & $\ln A$ & $\mathrm{R}^{2}$ \\
\hline $3-50 \%$ & 67.713 & 13.090 & 0.989 \\
\hline $3-60 \%$ & 67.298 & 12.958 & 0.974 \\
\hline $3-70 \%$ & 67.383 & 12.974 & 0.959 \\
\hline
\end{tabular}

Table 5. Rate equations at different temperatures.

\begin{tabular}{|lll|}
$T\left({ }^{\circ} \mathrm{C}\right)$ & Rate equation & Total order \\
\hline 100 & $v=1.3 \cdot 10^{-4}[4]^{1.24}[5]^{0.53}$ & 1.8 \\
110 & $v=3.7 \cdot 10^{-4}[4]^{1.08}[5]^{0.51}$ & 1.6 \\
120 & $v=5.0 \cdot 10^{-4}[4]^{1.20}[5]^{0.52}$ & 1.7 \\
130 & $v=8.1 \cdot 10^{-4}[4]^{1.12}[5]^{0.50}$ & 1.6 \\
140 & $v=1.1 \cdot 10^{-3}[4]^{1.41}[5]^{0.48}$ & 1.9 \\
\end{tabular}

$\Delta H$ values could also be calculated from the integration of the area involving the heat transferred by the reaction. These values are shown in Table 6 and are very close to the average value $\left(76.31 \mathrm{~kJ} \cdot \mathrm{mol}^{-1}\right)$ obtained from the integration of non-isothermal DSC curves. Discrepancies among these values are due to the difficulty of the isothermal plot integration (above) using an accurate baseline.

\begin{tabular}{|lccc|}
\hline \multicolumn{2}{|c|}{ Table 6. Integrated $\Delta H$ values obtained at different heating rates. } \\
$\beta\left({ }^{\circ} \mathrm{C} \cdot \mathrm{min}^{-1}\right)$ & $\Delta H\left(\mathrm{~kJ} \cdot \mathrm{mol}^{-1}\right)$ & $\beta\left({ }^{\circ} \mathrm{C} \cdot \mathrm{min}^{-1}\right)$ & $\Delta H\left(\mathrm{~kJ} \cdot \mathrm{mol}^{-1}\right)$ \\
\hline 100 & 67.13 & 130 & 75.59 \\
110 & 77.97 & 140 & 63.89 \\
120 & 69.89 & 150 & [a] \\
\hline [a] Not determined because a very fast reaction occurred.
\end{tabular}

The total process can therefore be deconvoluted in the two participating mechanisms named autocatalytic $\left\{k_{2}[4]_{0}[1-\alpha][4]_{0}\right.$ $[\alpha]\}$ and non-autocatalytic $\left\{k_{1}[4]_{0}[1-\alpha]\right\}$. If pseudo first order conditions are assumed the reaction rate can be expressed as show in equation (8), which can also be written as equation (9). ${ }^{[21]}$

$$
\begin{aligned}
& {[\mathbf{4}]_{0}[\mathrm{~d} \alpha / \mathrm{d} t]=\mathrm{k}_{1}[4]_{0}[1-\alpha]+\mathrm{k}_{2}[4]_{0}[1-\alpha][4]_{0}[\alpha]} \\
& {[\mathrm{d} \alpha / \mathrm{d} t] \cdot[1-\alpha]^{-1}=\mathrm{k}_{1}+\mathrm{k}_{2}[4]_{0}[\alpha]} \\
& {[\mathrm{d} \alpha / \mathrm{d} t] \cdot[1-\alpha]^{-1.2}=\mathrm{k}_{1}+\mathrm{k}_{2}[4]_{0}[\alpha]^{0.5}}
\end{aligned}
$$

The plot of equation (9) $\left\{[\mathrm{d} \alpha / \mathrm{d} t] \cdot[1-\alpha]^{-1}\right\}$ vs $[\alpha]$ did not afford any straight line at all, but exponential curves, which 
demonstrates that the partial reaction orders are not equal for the same reagent/product en each term of the equation. Last tentative consisted in assuming 1.2 and 0.5 partial reaction orders for each component, but the lineal regression failed as well. So, it is very difficult to know the exact contribution of each mechanism using all this information, and the reaction order of the imine $\mathbf{4}$ seems to be different in both mechanisms.

According to all these results, the exothermic 1,3-DC would follow an approximate energetic profile similar to that represented in Figure 10 and equation (11). The rate determining step being the generation of the 1,3-dipole (intermediate) after a thermal [1,2]-prototropy, immediately after the formation of $\mathbf{2}$, the cycloaddition occurs. This profile represents the whole process where both the catalyzed and non-catalyzed processes, coexist.

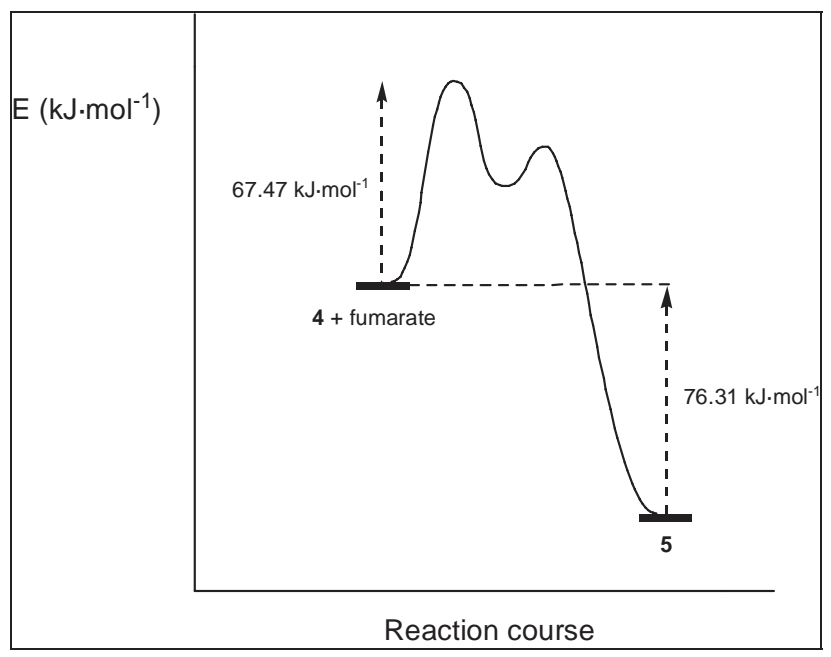

Figure 10. Energetic profile of the 1,3-DC of 4 and diisobutyl fumarate.

$4 \underset{k_{-1}}{\stackrel{k_{1}}{\longrightarrow}}$ dipole + fumarate $\stackrel{k_{2}}{\longrightarrow} \mathbf{5}$

\section{Conclusion}

In summary, DSC can be considered as a simple and fast technique (complementary with TLC, GC, HPLC, etc.) for monitoring organic chemical processes as well as for the determination of several kinetic parameters. For the particular case of the 1,3-DC using azomethine ylides, generated by thermal [1,2]-prototropy from imine 4 are necessary 67.47 $\mathrm{kJ} \cdot \mathrm{mol}^{-1}$ for the reaction to occur with diisobutyl fumarate. The exothermal reaction has an enthalpy of $76.3 \mathrm{~kJ} \cdot \mathrm{mol}^{-1}$, which is an average of the measurements done in non-isothermal experiments up to $10^{\circ} \mathrm{C} \cdot \mathrm{min}^{-1}$. The total reaction order is 1.7 , that means, 1.2 partial reaction order for the imine 4 and 0.5 partial reaction order for the catalyst 5 . Kissinger, and OFW models applied to dynamic experiments, reported an approximate value of $E_{a}$ and $\ln A$, even though could not provide information on reaction order as an overall first order reaction is assumed in these models. Possibly, the low impact of the real concentration in Kissinger and OFW models applied onto dynamic DSC curves, which work with second derivatives at isoconversional conditions, also helps to get a good and fast initial approach for the kinetic analysis of a reaction. In our opinion, more versatile BD model applied over dynamic experiments did not afford better results than the analogous obtained by Kissinger and OFW models in a 3-10 ${ }^{\circ} \mathrm{C} \cdot \mathrm{min}^{-1}$ heating rate range. $\mathrm{BD}$ reported a total reaction order similar to 1 , but with higher both $E_{a}$ and $\operatorname{In} A$ parameters. Dynamic tests ensure a suitable and fast calculation of the reaction enthalpy, rather than the determination employing isothermal experiments. However, NLR of isothermal data afforded very constant values of $E_{a}, \ln A$ and total reaction orders and allow to write the rate equation for the thermal 1,3-DC between imino ester $\mathbf{4}$ and diisobutyl fumarate. The existence of autocatalysis by the reaction product can be easily detected by studying the plot of $E_{a}$ values vs conversions at different heating rates, and by the bell-shape form of the heat flow vs $t$ or by the S-form of conversions vs $t$ employing isothermal DSC curves. Due to the generation of the 1,3-dipole is rate determining step, kinetic parameters are related to the formation of the reactive species of phenylglycinate. In the same way, autocatalysis may be operating on the tautomeric equilibrium.

\section{Experimental Section}

See supporting information.

Supporting Information (see footnote on the first page of this article).

\section{Acknowledgements}

This work has been supported by the Spanish Ministerio de Ciencia e Innovación (MICINN) (Consolider INGENIO 2010 CSD2007-00006, CTQ2010-20387, FEDER, Generalitat Valenciana (PROMETEO/2009/039), and by the University of Alicante.

Keywords: cycloaddition / DSC / kinetics / autocatalysis / azomethine ylides

Received: ((will be filled in by the editorial staff))

Published online: ((will be filled in by the editorial staff)) 
Entry for the Table of Contents (Please choose one layout only)

Layout 1:

\section{FULL PAPER}

Text for Table of Contents.

Author(s), Corresponding Author(s)*

Page No. - Page No.

((The TOC Graphic should not exceed

Title the size of this area))

Layout 2:

\section{FULL PAPER}

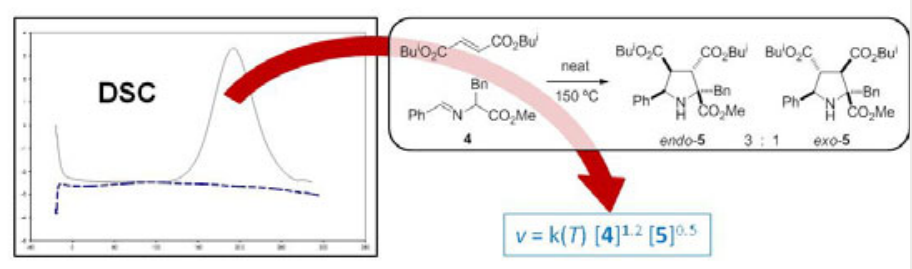

Kinetics of 1,3-dipolar cycloaddition involving azomethine ylides, generated from thermal $[1,2]$-prototropy of the co- rresponding imino ester, has been evaluated through differential scanning calorimetry (DSC).
Juan Mancebo-Aracil, María J. MuñozGuillena, Ion Such-Basáñez and José M. Sansano-Gil

Page No. - Page No.

Kinetic Study of Thermal 1,3-Dipolar Cycloaddition of Azomethine Ylides using Differential Scanning Calorimetry as Monitoring Window

\section{References}

[1] a) Comprehensive Handbook of Calorimetry and Thermal Analysis, M. Sorai, Ed. John Wiley \& Sons, Chichester, 2004. b) Handbook of Thermal Analysis and Calorimetry, P. K. Gallagher, Ed. Vol. 1-5, Elsevier Science, Amsterdam, 2003̃2007. c) Principles and Applications of Thermal Analysis, P. Gabbot, Ed. Blackwell Publishing, Oxford, 2008. d) Differential Scanning Calorimetry, G. Höhne, W. F. Hemminger, H.-J. Flammersheim, Eds. SpringerVerlag, Heidelberg, 2010. e) Modulated Temperature Differntial Scanning Calorimetry: Theoretical and Practical Applications in Polymer Characterization (Hot Topics in Thermal Analysis and Calorimetry), M. Reading, D. J. Hourston. Eds. Springer, Dordretch, 2010.

[2] T. F. J. Pjpers, V. B. F. Mathot, B. Goderis, R. L. Scherrenberg, E. W. van der Vegte, Macromolecules 2002, 35, 3601-3613.

[3] Thermal Analysis UserCom Series, Mettler Toledo Inc. Publishing, 1995-2012.

[4] a) K. A. Connors, in Chemical Kinetics, The Study of Reaction Rates in Solution, VCH Publishers, New York, 1990. b) R. I. Masel, in Chemical Kinetics and Catalysis, John Wiley \& Sons, New York, 2001. c) M. R. Wright, in An Introduction to Chemical Kinetics, John Wiley \& Sons, Chichester, 2004.

[5] See reference 1b, vol. 1, chp. 3, 147-224. 
[6] The activation energy of the Diels-Alder reaction between hexachlorocyclopentadiene and cyclopentene was reported by using an excess of hexachlorocyclopentadiene and assuming pseudo-first order kinetics: J. A. Belichmeiera, H. K. Cammenga, P. B. Schneiderb, A. G. Steerb, Thermochim. Acta 1998, 310, 147-151.

[7] For this analysis the main features of the selected reaction must be precisely designed. For example, a small homogeneous liquid mixture of both components is required $(2-5 \mathrm{mg})$ in order to promote the fast heat transfer to the sample and to avoid, as much as possible, phase changes and diffusion problems. The boiling point of the reactants must be higher than the temperature at which to the reaction occurs for avoiding undesired processes which may contribute to the total energy changes observed, thus complicating the analysis of the results.

[8] R. Hüisgen, Angew. Chem. Int. Ed. 1963, 2, 565-632.

[9] For recent computational studies concerning 1,3-DC of azomethine ylides see: a) T. K. Das, M. Banerjee, J. Phys. Org. Chem. 2010, 23, 148-155. b) L. R. Domingo, E. Chamorro, P. Pérez, Lett. Org. Chem. 2010, 7, 432-439. c) A. de Cózar, F. P. Cossío, Phys. Chem. Chem. Phys. 2011, 13, 10858-10868, and references cited therein.

[10] For general reviews displaying wide applications of 1,3-DC of azomethine ylides see: a) Synthetic Applications of 1,3-Dipolar Cycloaddition Chemistry Towards Heterocycles and Natural Products, A. Padwa, W. H. Pearson, Eds. John Wiley \& Sons, New Jersey, 2003. b) C. Nájera, J. M. Sansano, Curr. Org. Chem. 2003, 7, 1105-1150. c) W. Eberbach, Sci. Synth. 2004, 27, chp. 11, 441-498. d) I. Coldham, R. Hufton, Chem. Rev. 2005, 105, 2765-2809; e) V. Nair, T. D. Suja, Tetrahedron 2007, 63, 12247-12275. d) A. Padwa, S. K. Bur, Tetrahedron 2007, 63, 5341-5378.

[11] A pseudo-diradical character of the three-atom components involved in this [3+2] cycloaddition has been found using electron localization function (ELF) analysis in order to explain the large reactivity of these species, see ref. $9 \mathrm{~b}$

[12] The enantioselective 1,3-DC of azomethine ylides is a prolific area in organic synthesis and it is frequently being reviewed. For selected recent examples, see: a) H. Pellissier, Tetrahedron 2007, 63, 3235-3285. b) C. Nájera, J. M. Sansano in Topics in Heterocyclic Chemistry, A. Hassner, Ed. Springer-Verlag Berlin-Heidelberg, 2008, vol. 12, pp. 117-145; c) L. M. Stanley, M. P. Sibi, Chem. Rev. 2008, 108, 2887-2902; d) M. Álvarez-Corral, M. Muñoz-Dorado, I. Rodríguez-García, Chem. Rev. 2008, 108, 3174-3198. e) M. Naodovic, H. Yamamoto, Chem. Rev. 2008, 108, 3132-3148. f) C. Nájera, J. M. Sansano, M. Yus, J. Braz. Chem. Soc. 2010, 21, 377-412. g) M. Kissane, A. R. Maguire, Chem. Soc., Rev. 2010, 39, 845-883. h) J. Adrio, J. C. Carretero, Chem. Commun. 2011, 47, 6784-6794.

[13] The 1,3-DC of azomethine ylides with imines (including self-cycloaddition in the absence of a trapping agent) has been employed in the synthesis of $\alpha, \beta$-dehydro- $\alpha$-amino acid derivatives: a) P. W. Groundwater, T. Sharif, A. Arany, D. E. Hibbs, M. B. Hursthouse, M. Nyerges, Tetrahedron Lett. 1998, 39, 1433-1436. b) P. W. Groundwater, T. Sharif, A. Arany, D. E. Hibbs, M. B. Hursthouse, I. Garnett, M. Nyerges, J. Chem. Soc, Perkin Trans. 1 1998, 2837-2846.

[14] See for instance: a) S. Jacquot-Rousseau, G. Schmitt, A. Khatyr, M. Knorr, M. M. Kubicki, E. Vigier, O. Blacque, Eur. J. Org. Chem. $2006,1555-1562$. b) P. Elo, A. Pärssinen, M. Nieger, M. Leskelä, T. Repo, J. Organometal. Chem. 2009, 694, 2927-2933.

[15] Fast and accurate algorithm for the simulation of NMR spectra of large spin systems can be performed: A. M. Castillo, L. Patiny, J. Wist, J. Magn.

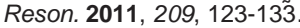

[16] K. Tanaka, F. Toda, Chem. Rev. 2000, 100, 1025-1074.

[17] The reaction of Scheme 2 was evaluated employing different solvents such as DMSO, triglyme, mesitylene. The generation of heterocycle 3 was slower than the corresponding transformation carried out in the absence of solvent.

[18] Under these reaction conditions a 2.4:1:1 endo:exo:non characterized diastereoisomer was obtained according to ${ }^{1} \mathrm{H}$ NMR experiments.

[19] There are not many examples in the literature concerning kinetics of 1,3-DC involving azomethine ylides: K. Elender, P. Riebel, A. Weber, J. Sauer, Tetrahedron 2000, 56, 4261-4265.

[20] Handbook of Thermal Analysis, T. Hatakeyama, Z. Liu, Eds. John Wiley \& Sons, New York, 1998, chp. 4.

[21] F. Mata-Pérez, J. Pérez-Benito, J. Chem. Educ. 1987, 64, 925-927.

[22] a) TA-073, TA Instruments, http://www.tainst.com; b) TA-143A, TA Instruments, http://www.tainst.com.

[23] H. E. Kissinger, Anal. Chem. 1957, 29, 1702-1706.

[24] H.J. Borchardt, F. Daniels, J. Am. Chem. Soc. 1959, 79, 41-46.

[25] a) T. J. Ozawa, Therm. Anal. 1970, 2, 301-324. b) J. H. Flynn, L. A. Wall, J. Res. Nat. Bur. Stand 1966, 70A, 487-493.

[26] a) Z.-H. Chen, F.-Q. Zu, X.-F. Li, J. Yu, Y. Xi, R.-R. Shen, J. Phys.: Condens. Matter 2007, 19, 116106. b) S. Matecic-Musanic, I. Fiamengo-Houra, M. Suceska, Central Eur. J. Energ. Mater. 2010, 7, 233-251.

[27] J. Farjas, N. Butchosa, P. Roura, J. Therm. Anal. Calorim. 2010, 102, 615-625

[28] P. E. Sánchez-Jiménez, J. M. Criado, A. Pérez-Maqueda, J. Therm. Anal. Cal. 2008, 94, 427-432.

[29] ASTM E698-11, ASTM Int., West Conshohocken, US.

[30] See supporting information.

[31] ASTM E2070-00, ASTM Int., West Conshohocken, US.

[32] MLR was performed using solver application tool of Microsoft Excell.

[33] J. Wang, M.-P. G. Laboire, M. P. Wolcott, J. Appl. Polym. Sci. 2007, 105, 1289-1296.

[34] The initial concentration of the fumarate was not considered in this equation because has a 0 reaction order according to the pseudo-order techniques. See isothermal tests comparing different proportions of reagents.

[35] S. V. Vyazovkin, A. I. Lesnikovich, Thermochim. Acta 1990, 165, 273-280.

[36] The elimination of the autocatalytic contribution $\{\mathrm{m} \ln [\alpha]\}$ of equation (6) represented a very poor mathematical correlation with the experimental DSC curve. 


\section{SUPPORTING INFORMATION}

Kinetic Study of Thermal 1,3-Dipolar Cycloaddition of Azomethine Ylides using Differential Scanning Calorimetry as Monitoring Window

Juan Mancebo-Aracil, ${ }^{a}$ María J. Muñoz-Guillena, ${ }^{\mathrm{b}}$ Ion Such-Basáñez ${ }^{\mathrm{b}}$ and José M. Sansano-Gil. ${ }^{\text {a* }}$

åDepartamento de Química Orgánica e Instituto de Síntesis Orgánica (ISO), Universidad de Alicante, 03080-Alicante (Spain).

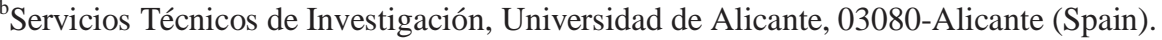

Correspondence should be addressed to JMS-G (jmsansano@ua.es)

Table of Contents

2. Synthesis of Iminoesters

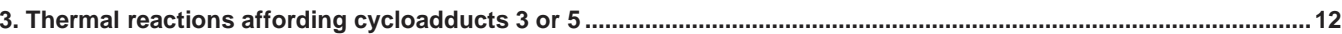

4. $\ln \left(\beta \cdot T^{-2}\right)$ vs $T^{-1}$ for the calculation of $E_{a}$ and $\ln A$ following Kissinger's model.....................................................13

5. $\ln (\beta)$ vs $T^{-1}$ for the calculation of $E_{a}$ and InA following Ozawa's model ..............................................................13

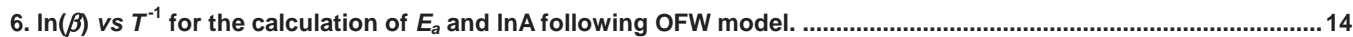

7. Dynamic DSC curves at different heating rates $(\beta)$ (complete data).......................................................................14

8. Table including all the kinetic parameters obtained by application

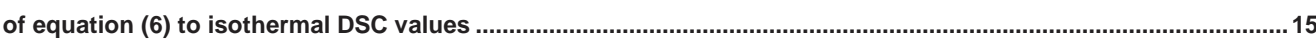

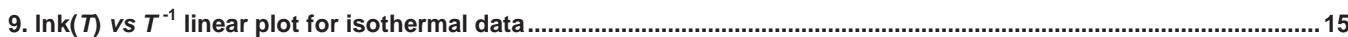

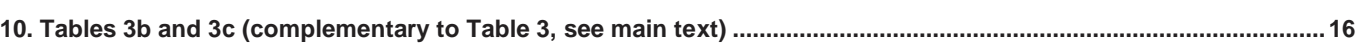

1. General

Aldehydes were also distilled prior to use for the elaboration of the iminoesters. Only the structurally most important peaks of the IR spectra (recorded using a Nicolet 510 P-FT and a Jasco FTIR 4100) are listed. ${ }^{1} \mathrm{H}$ NMR (300 MHz) and ${ }^{13} \mathrm{C} \mathrm{NMR} \mathrm{(75} \mathrm{MHz)} \mathrm{spectra} \mathrm{were} \mathrm{obtained} \mathrm{using} \mathrm{a} \mathrm{Bruker} \mathrm{AC-300} \mathrm{with} \mathrm{CDCl} 3$ as solvent and TMS as internal standard unless otherwise stated. Low-resolution electron impact (GC-EI) mass spectra were obtained at 70 eV using a Shimadzu QP-5000, and high-resolution mass spectra were obtained using a Finnigan VG Platform. HRMS (GC-EI) were recorded using a Finnigan MAT 95S instrument. Analytical TLC was performed using Schleicher \& Schuell F1400/LS silica gel plates, and the spots were visualized under UV light $(\lambda=254 \mathrm{~nm})$. For flash chromatography, we employed Merck silica gel $60(0.040-0.063 \mathrm{~mm})$. CEM Discover and Explorer-Coolmate accessory were employed in the microwave-assisted reactions for the generation of iminoesters.

Mettler Toledo Microbalance MT5 was employed for the measurement of small amounts of sample placed in sealed hermetic crucibles. DSC measurements were registered in a modulated MDSC TA Instruments, model Q100 with autosampler and RCS and LNCS systems for running experiments at low temperature.

The freshly prepared mass must be kept low $(<5 \mathrm{mg})$ and it is preferred that the sample is placed in a hermetically sealed pan. After every experiment the mass of the sample must be in order to ensure that no mass loss has taken place during the experiment.

\section{Synthesis of Iminoesters}

To a suspensión of glycine methyl ester hydrochloride or phenylalanine methyl ester hydrochloride $(6 \mathrm{mmol})$ in dichloromethane $(5 \mathrm{~mL})$ benzaldehyde ( 6 $\mathrm{mmol}, 636.7 \mathrm{mg})$ and $\mathrm{Et}_{3} \mathrm{~N}(1.1 \mathrm{eq}, 917 \mu \mathrm{L})$ were successively added. The sealed tube, containing this mixture, was irradiated in a microwave reactor (40 W), 
and $40 \stackrel{\circ}{\circ}$ for $1 \mathrm{~h}$. Then, dichloromethane was evaporated under vacuo and water $(15 \mathrm{~mL})$ was added. The aqueous phase was extracted with ethyl acetate $(3 \times 10 \mathrm{~mL})$, the organic layer was separated dried $\left(\mathrm{MgSO}_{4}\right)$, and evaporated yielding very pure iminoesters $\mathrm{A}$ and $\mathrm{B}$ in $94 \%$ and $96 \%$, respectively.

\section{Thermal reactions affording cycloadducts 3 or 5}

The homogeneous mixture of iminoester and dipolarophile was prepared in the corresponding proportion and submitted to the heating conditions at the selected temperature (see text) obtaining cycloadducts $\mathbf{3}$ or $\mathbf{5}$.

$\left(2 R^{\star}, 4 S^{\star}, 5 S^{\star}\right)$-Methyl 1-(methoxycarbonyImethyl)-2,5-diphenylimidazolidine-4-carboxylate (3 major estereoisomer): Sticky pale yellow oil; $R_{f} 0.73$ (7/3 $n$ hexane/ethyl acetate); IR (neat) $v_{\max } 3250,1735 \mathrm{~cm}^{-1} ;{ }^{1} \mathrm{H}$ NMR $\delta 2.70$ (br. s, $1 \mathrm{H}, \mathrm{NH}$ ), 3.13 (s, 3H, $\left.\mathrm{CH}_{2} \mathrm{CO}_{2} \mathrm{Me}\right), 3.22,3.34\left(2 \mathrm{~d}, J=18 \mathrm{~Hz}, 2 \mathrm{H}, \mathrm{CH}_{2} \mathrm{CO}\right), 3.54$ (s, $\left.3 \mathrm{H}, \mathrm{CHCO}_{2} \mathrm{Me}\right), 4.37\left(\mathrm{~d}, \mathrm{~J}=9 \mathrm{~Hz}, 1 \mathrm{H}, \mathrm{CHCO}_{2} \mathrm{Me}\right), 4.69(\mathrm{~d}, \mathrm{~J}=9 \mathrm{~Hz}, 1 \mathrm{H}, \mathrm{CHCHCO}), 5.09\left(\mathrm{~s}, 1 \mathrm{H}, \mathrm{CHN}_{2}\right), 7.31-7.81(\mathrm{~m}, 10 \mathrm{H}, \operatorname{ArH}) ;{ }^{13} \mathrm{C} \mathrm{NMR} \delta 47.7\left(\mathrm{CH}_{2}\right)$, 51.3, $51.6\left(2 \times \mathrm{OCH}_{3}\right), 64.9\left(\mathrm{CHCO}_{2}\right), 67.4\left(\mathrm{CNCH}_{2}\right), 79.9\left(\mathrm{CN}_{2}\right), 128.1,128.2,128.7,129.0,129.5,134.6,138.6,140.6(\operatorname{ArC}), 171.1,171.8,(2 \times \mathrm{CO}) ; \mathrm{MS}(\mathrm{El}-$ GC) $m / z 354\left(M^{+}+1,<1 \%\right), 162$ (42), 75 (18), 104 (10), 91 (100), 74 (17); HRMS calculated for $\mathrm{C}_{20} \mathrm{H}_{22} \mathrm{~N}_{2} \mathrm{O}_{4}-\mathrm{C}_{10} \mathrm{H}_{12} \mathrm{~N}_{2} \mathrm{O}_{2}: 162.0581$, found: 162.0578.

$\left(2 R^{\star}, 4 S^{\star}, 5 R^{\star}\right)$-Methyl 1-(methoxycarbonylmethyl)-2,5-diphenylimidazolidine-4-carboxylate (3 minor stereoisomer): Sticky pale yellow oil; $R_{f} 0.73$ (7/3 $n$ hexane/ethyl acetate); IR (neat) $v_{\max } 3250,1735 \mathrm{~cm}^{-1} ;{ }^{1} \mathrm{H}$ NMR $\delta 2.75$ (br. s, $\left.1 \mathrm{H}, \mathrm{NH}\right), 3.19,3.17\left(2 \mathrm{~d}, \mathrm{~J}=18 \mathrm{~Hz}, 2 \mathrm{H}, \mathrm{CH}_{2} \mathrm{CO}\right), 3.52\left(\mathrm{~s}, 3 \mathrm{H}, \mathrm{CH} \mathrm{CO}_{2} \mathrm{Me}\right), 3.78$ (s, 3H, $\mathrm{CHCO}_{2} \mathrm{Me}$ ), 3.91 (d, J = $\left.6 \mathrm{~Hz}, 1 \mathrm{H}, \mathrm{CHCO}_{2} \mathrm{Me}\right), 4.48(\mathrm{~d}, \mathrm{~J}=6 \mathrm{~Hz}, 1 \mathrm{H}, \mathrm{CHCHCO}), 5.15\left(\mathrm{~s}, 1 \mathrm{H}, \mathrm{CHN}_{2}\right), 7.30-7.91(\mathrm{~m}, 10 \mathrm{H}, \mathrm{Ar} H) ;{ }^{13} \mathrm{C} \mathrm{NMR} \delta 47.8\left(\mathrm{CH}_{2}\right)$, 52.2, $52.4\left(2 \times \mathrm{OCH}_{3}\right), 67.1\left(\mathrm{CHCO}_{2}\right), 68.7\left(\mathrm{CNCH}_{2}\right), 79.8\left(\mathrm{CN}_{2}\right), 128.1,128.2,128.7,129.1,129.9,134.6,138.9,140.1(\mathrm{ArC}), 171.0,173.4(2 \times \mathrm{CO})$; $\mathrm{MS}(\mathrm{EI}-$ GC) $m / z 354\left(\mathrm{M}^{+}+1,<1 \%\right), 162$ (42), 75 (18), 104 (10), 91 (100), 74 (17); HRMS calculated for $\mathrm{C}_{20} \mathrm{H}_{22} \mathrm{~N}_{2} \mathrm{O}_{4}-\mathrm{C}_{10} \mathrm{H}_{12} \mathrm{~N}_{2} \mathrm{O}_{2}: 162.0581$, found: 162.0578.

$\left(2 S^{\star}, 3 S^{\star}, 4 S^{\star}, 5 R^{\star}\right)$-3,4-Diisobutyl 2-methyl 2-benzyl-5-phenylpyrrolidine-2,3,4-tricarboxylate (endo-5): Pale yellow oil; $R_{f} 0.67$ (7/3 $n$-hexane/ethyl acetate); IR (neat) $v_{\max } 3400,1728 \mathrm{~cm}^{-1} ; 1 \mathrm{H} \mathrm{NMR} \delta 0.67,0.68,0.99,1.00\left(4 \mathrm{x} \mathrm{d}, J=6 \mathrm{~Hz}, 2 \times \mathrm{CHCH}_{3}\right), 1.68,1.99(2 \times \mathrm{m}, 2 \mathrm{H}, 2 \times \mathrm{CHCH}), 2.80(\mathrm{br}$. s, $1 \mathrm{H}$, $\mathrm{NH}), 3.25,3.39\left(2 \mathrm{xd}, J=12 \mathrm{~Hz}, \mathrm{CH}_{2} \mathrm{Ph}\right.$ ), 3.40 (dd, $J=11$ and $9 \mathrm{~Hz}, 1 \mathrm{H}, \mathrm{CHCHN}$ ), 3.60 (d, $\left.J=9 \mathrm{~Hz}, 1 \mathrm{H}, \mathrm{CHCBn}\right), 3.69$ (s, 3H, OCH3), $3.70-3.76 \mathrm{and} 3.90-$ $3.95\left(2 \times \mathrm{m}, 4 \mathrm{H}, 2 \times \mathrm{CH}_{2} \mathrm{CH}\right), 4.04(\mathrm{~d}, \mathrm{~J}=11 \mathrm{~Hz}, 1 \mathrm{H}, \mathrm{CHN}), 7.23-7.40(\mathrm{~m}, 10 \mathrm{H}, \mathrm{ArH}) ;{ }^{13} \mathrm{C} \mathrm{NMR} \delta 18.8,18.9,19.2,19.3\left(4 \times \mathrm{CH}_{3} \mathrm{CH}\right), 27.6,27.7\left(2 \times \mathrm{CHCH}_{3}\right)$, $43.2\left(\mathrm{CH}_{2} \mathrm{Ph}\right), 52.6\left(\mathrm{OCH}_{3}\right), 55.1(\mathrm{CHCHN}), 56.0(\mathrm{CHCBn}), 65.5(\mathrm{CHN}), 71.0,71.6\left(2 \times \mathrm{CH}_{2} \mathrm{O}\right), 127.1,127.8,128.3,128.7,130.1,130.7,136.1,140.3(\mathrm{ArC})$, 171.1, 171.2, 174.1 (3 x CO); MS (EI-GC) m/z 495 (M+1, <1\%), 436 (6), 404 (25), 362 (12), 331 (20), 330 (100), 228 (25), 202 (20), 170 (12), 91 (31); HRMS calculated for $\mathrm{C}_{29} \mathrm{H}_{37} \mathrm{NO}_{6}-\mathrm{C}_{2} \mathrm{H}_{3} \mathrm{O}_{2}: 436.2458$, found: 436.2460 .

$\left(2 S^{\star}, 3 R^{\star}, 4 R^{\star}, 5 R^{\star}\right)$-3,4-Diisobutyl 2-methyl 2-benzyl-5-phenylpyrrolidine-2,3,4-tricarboxylate (exo-5): Pale yellow oil; $R_{f} 0.67$ (7/3 $n$-hexane/ethyl acetate); $\mathrm{IR}$ (neat) $v_{\max } 3400,1728 \mathrm{~cm}^{-1}$; $1 \mathrm{H} \mathrm{NMR} \delta 0.65,0.69,1.01,1.03\left(4 \mathrm{x} \mathrm{d}, \mathrm{J}=6 \mathrm{~Hz}, 2 \times \mathrm{CHCH}_{3}\right), 1.56,2.01(2 \times \mathrm{m}, 2 \mathrm{H}, 2 \times \mathrm{CHCH} 3), 2.85$ (br. s, $\left.1 \mathrm{H}, \mathrm{NH}\right), 2.92$, $3.17\left(2 \mathrm{xd}, J=12 \mathrm{~Hz}, \mathrm{CH}_{2} \mathrm{Ph}\right.$ ), 3.48 (dd, $J=9$ and $\left.7.5 \mathrm{~Hz}, 1 \mathrm{H}, \mathrm{CHCHN}\right), 3.74-3.78\left(\mathrm{~m}, 2 \mathrm{H}, \mathrm{CH}_{2} \mathrm{CH}\right), 3.77(\mathrm{~s}, 3 \mathrm{H}, \mathrm{OCH} 3), 3.89-4.01(\mathrm{~m}, 3 \mathrm{H}, \mathrm{CHCBn}$ and

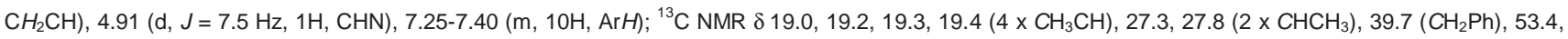
$53.5\left(\mathrm{OCH}_{3}, \mathrm{CHCHN}\right), 54.6(\mathrm{CHCBn}), 63.1(\mathrm{CHN}), 71.3,71.5\left(2 \times \mathrm{CH}_{2} \mathrm{O}\right), 126.9,127.7,127.8,128.1,128.2,129.7,136.4,140.0(\mathrm{ArC}), 170.9,171.0,173.7(3$ x CO); MS (El-GC) m/z 495 (M+1, <1\%), 436 (6), 404 (25), 362 (12), 331 (20), 330 (100), 228 (25), 202 (20), 170 (12), 91 (31); HRMS calculated for $\mathrm{C}_{29} \mathrm{H}_{37} \mathrm{NO}_{6}-\mathrm{C}_{2} \mathrm{H}_{3} \mathrm{O}_{2}: 436.2458$, found: 436.2460 . 
4. $\ln \left(\beta \cdot T^{-2}\right)$ vs $T^{-1}$ for the calculation of $E_{a}$ and $\ln A$ following Kissinger's model.

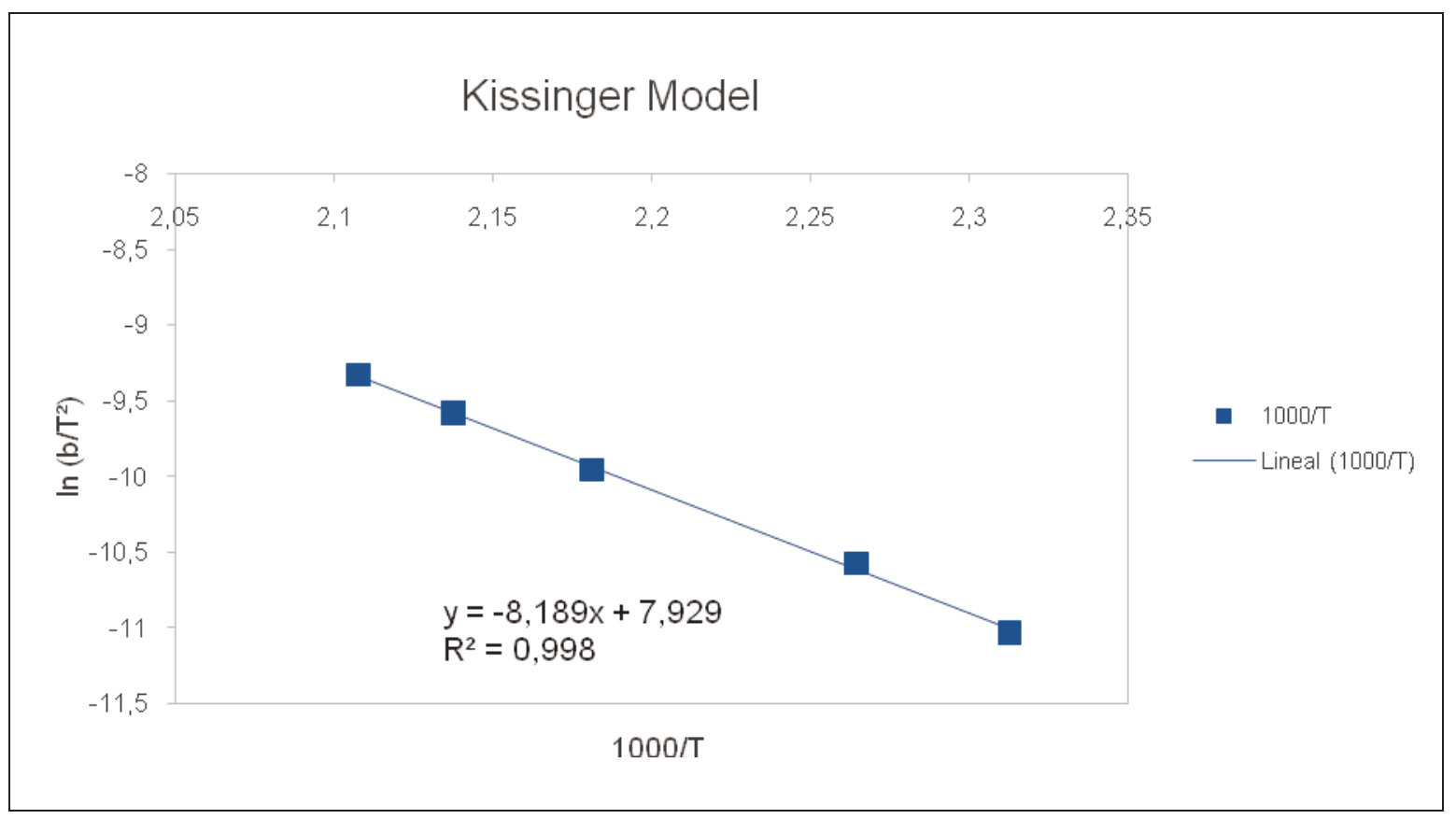

5. $\ln (\beta)$ vs $T^{-1}$ for the calculation of $E_{a}$ and InA following Ozawa's model.

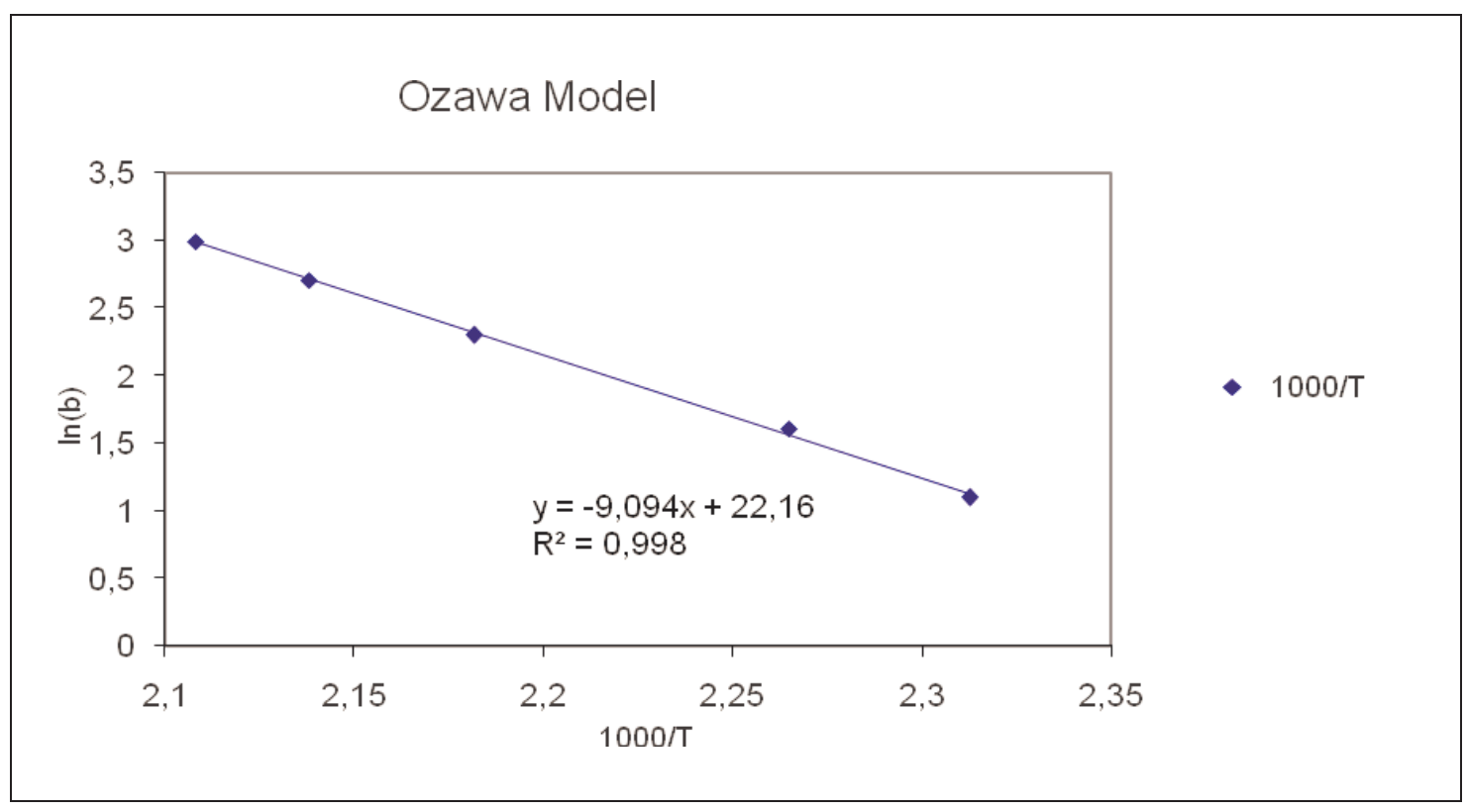


OFW model

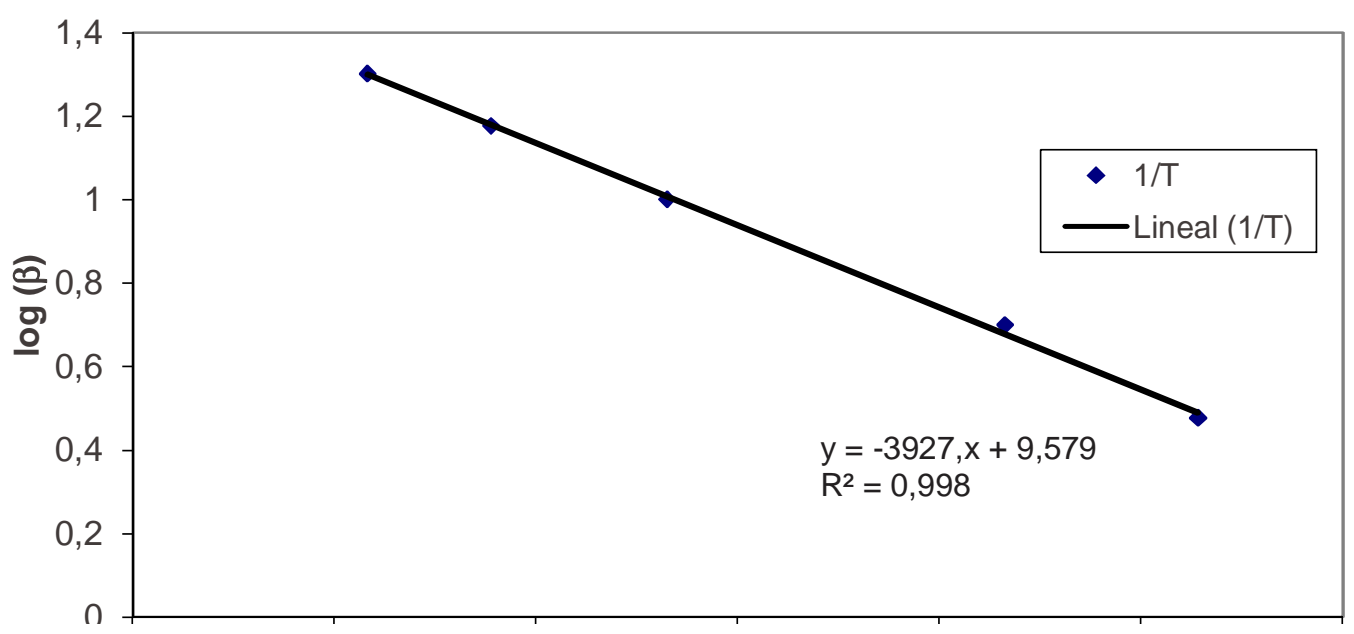

7. Dynamic DSC curves at different heating rates $(\beta)$.

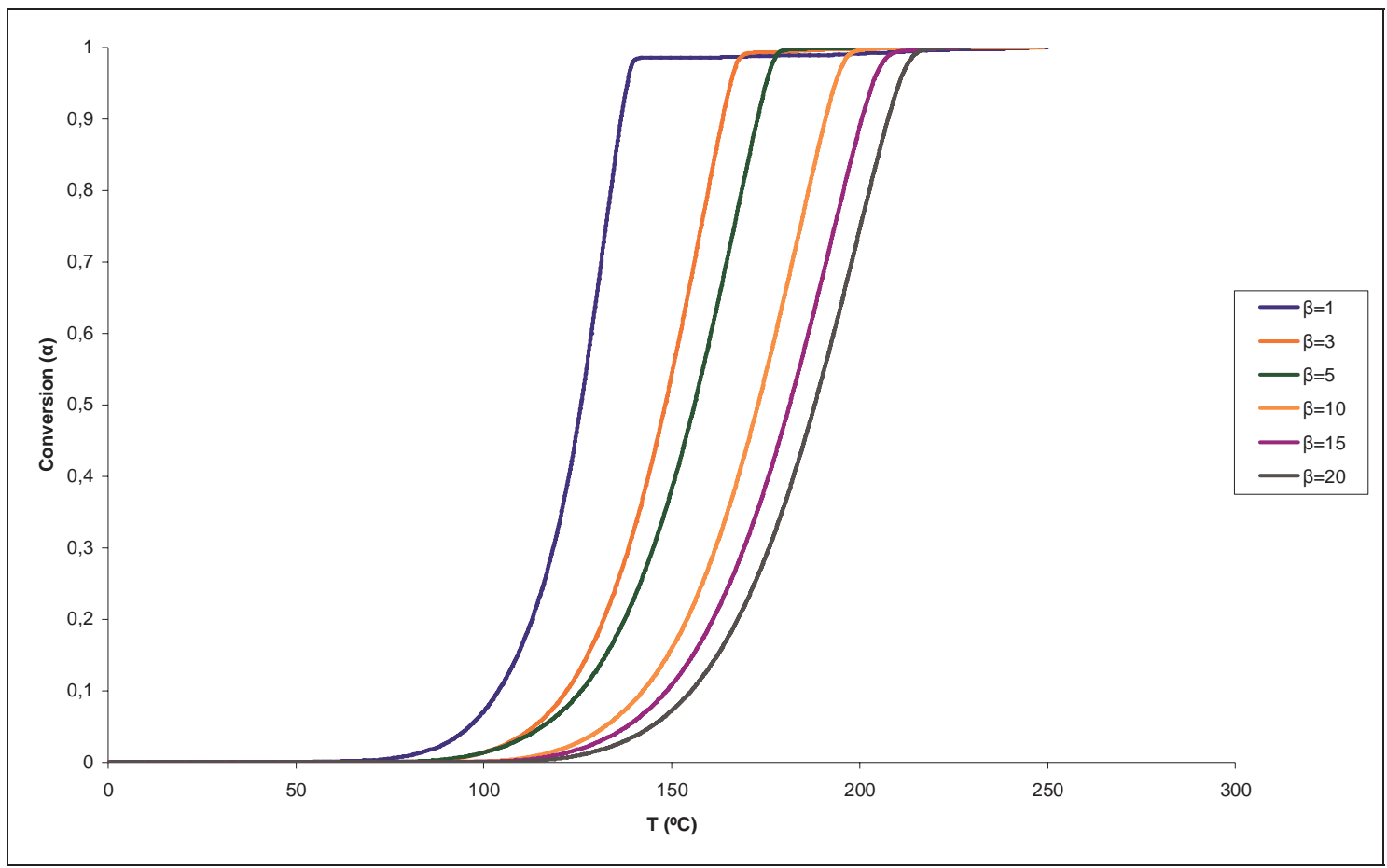


8. Table including all the kinetic parameters obtained by application of equation (6) to isothermal DSC values.

\begin{tabular}{|l|l|l|l|l|l|l|l|l|l|l|l|}
\cline { 3 - 11 } \multicolumn{2}{c}{} & \multicolumn{3}{c|}{ Lnk $(T)$} & \multicolumn{3}{c|}{$\mathrm{m}$} & \multicolumn{2}{c|}{$n$} \\
\hline$T\left({ }^{\circ} \mathrm{C}\right)$ & $T(\mathrm{~K})$ & $1 / T\left(\mathrm{~K}^{-1}\right)$ & $\alpha=0.5$ & $\alpha=0.6$ & $\alpha=0.7$ & $\alpha=0.5$ & $\alpha=0.6$ & $\alpha=0.7$ & $\alpha=0.5$ & $\alpha=0.6$ & $\alpha=0.7$ \\
\hline 100 & 373.16 & 2.6798 & -9.0461 & -8.9857 & -8.9587 & 0.545 & 0.529 & 0.517 & 1.360 & 1.220 & 1.145 \\
\hline 110 & 383.16 & 2.6099 & -7.8495 & -7.9187 & -7.9566 & 0.495 & 0.509 & 0.523 & 0.945 & 1.096 & 1.198 \\
\hline 120 & 393.16 & 2.5435 & -7.4569 & -7.5181 & -7.5333 & 0.509 & 0.520 & 0.528 & 1.105 & 1.240 & 1.280 \\
\hline 130 & 403.16 & 2.4804 & -7.1100 & -7.1274 & -7.1290 & 0.489 & 0.498 & 0.499 & 1.123 & 1.212 & 1.190 \\
\hline 140 & 413.16 & 2.4204 & -6.7965 & -6.7734 & -6.7593 & 0.485 & 0.480 & 0.475 & 1.458 & 1.407 & 1.370 \\
\hline
\end{tabular}

\begin{tabular}{|l|l|l|l|}
\cline { 2 - 4 } \multicolumn{1}{c|}{} & $\alpha=0.5$ & $\alpha=0.6$ & $\alpha=0.7$ \\
\hline Slope & -8144.5 & -8094.5 & -8104.8 \\
\hline Ordinate & 13.091 & 12.95 & 12.974 \\
\hline $\begin{array}{l}E_{a} \quad\left(\mathrm{~kJ} \cdot \mathrm{mol}^{-}\right. \\
\text {1) }\end{array}$ & 67.713 & 67.298 & 67.383 \\
\hline A & $4.85 \cdot 10^{5}$ & $4.21 \cdot 10^{5}$ & $4.31 \cdot 10^{5}$ \\
\hline$R^{2}$ & 0.92 & 0.95 & 0.95 \\
\hline
\end{tabular}

9. $\operatorname{lnk}(T)$ vs $T^{-1}$ linear plot for isothermal data (previous Table).

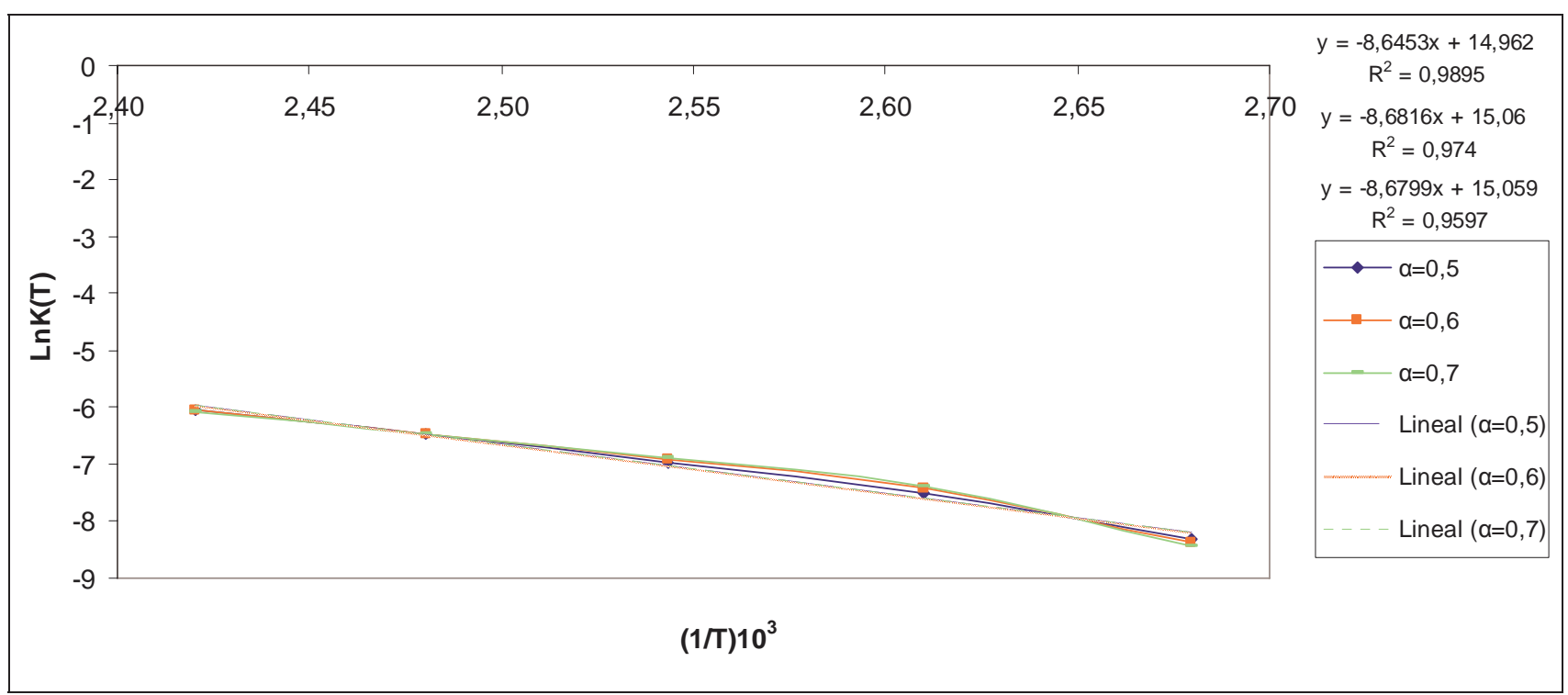


10. Tables $3 \mathrm{~b}$ and $3 \mathrm{c}$ (complementary to Table 3 , see main text)

Table 3b. Kinetic parameters obtained after NLR of different isothermal DSC curves in the range of 3-60\% conversion.

\begin{tabular}{|l|l|l|l|l|}
\hline$T\left({ }^{\circ} \mathrm{C}\right)$ & $\operatorname{lnk}(T)$ & $\mathrm{n}$ order & $\mathrm{m}$ order & $\begin{array}{l}\text { Lerror } \\
\mathrm{a}\end{array}$ \\
\hline 100 & -8.9857 & 1.220 & 0.529 & 10.24 \\
\hline 110 & -7.9817 & 1.096 & 0.509 & 6.25 \\
\hline 120 & -7.5181 & 1.240 & 0.520 & 7.22 \\
\hline 130 & -7.1274 & 1.212 & 0.498 & 5.55 \\
\hline 140 & -6.7965 & 1.407 & 0.480 & 2.26 \\
\hline
\end{tabular}

${ }^{\text {a }}$ Determined by solver mathematical NLR of the DSC plot.

Table 3c. Kinetic parameters obtained after NLR of different isothermal DSC curves in the range of 3-70\% conversion.

\begin{tabular}{|l|l|l|l|l|}
\hline$T\left({ }^{\circ} \mathrm{C}\right)$ & $\operatorname{lnk}(T)$ & $\mathrm{n}$ order & m order & Serror $^{2} \mathrm{a}$ \\
\hline 100 & -8.9587 & 1.145 & 0.517 & 15.12 \\
\hline 110 & -7.9566 & 1.197 & 0.523 & 7.61 \\
\hline 120 & -7.5333 & 1.280 & 0.528 & 7.57 \\
\hline 130 & -7.1290 & 1.190 & 0.499 & 2.0 \\
\hline 140 & -6.7793 & 1.370 & 0.475 & 2.4 \\
\hline
\end{tabular}

${ }^{\text {a }}$ Determined by solver mathematical NLR of the DSC plot. 